\title{
KERAGAMAN JENIS TUMBUHAN OBAT DI HUTAN PENDIDIKAN UNIVERSITAS SUMATERA UTARA KAWASAN TAMAN HUTAN RAYA TONGKOH KABUPATEN KARO SUMATERA UTARA
}

\section{(MEDICINAL PLANT SPECIES DIVERSITY ON EDUCATION FOREST OF UNIVERSITY OF NORTH SUMATRA AT TONGKOH GREAT FOREST PARK AREA IN KARO DISTRICT, NORTH SUMATERA)}

\author{
Eva Friska Br Sembiring ${ }^{1)}$, Indriyanto ${ }^{2)}$, dan Duryat ${ }^{2)}$ \\ ${ }^{1)}$ Mahasiswa Jurusan Kehutanan Fakultas Pertanian Universitas Lampung, \\ ${ }^{2)}$ Staf Pengajar Jurusan Kehutanan Fakultas Pertanian Universitas Lampung, \\ Jurusan Kehutanan Fakultas Pertanian Universitas Lampung \\ J1. Soemantri Brojonegoro No. 1 Bandar Lampung, 35145 \\ Email : evafriska_20@yahoo.com \\ Phone : 081370117741
}

\begin{abstract}
ABSTRAK
Taman Hutan Raya Tongkoh memiliki kondisi tempat tumbuh yang sangat baik untuk berbagai jenis tumbuhan berkhasiat obat. Penelitian tentang keragaman jenis tumbuhan obat di Taman Hutan Raya Tongkoh dibutuhkan karena minimnya informasi yang memadai tentang jenis-jenis tumbuhan obat yang ada di Taman Hutan Raya Tongkoh. Tujuan dari penelitian ini adalah untuk mengetahui jenis-jenis dan kelimpahan dari masing-masing jenis tumbuhan obat yang ada di blok pemanfaatan kawasan Tahura Tongkoh, Kabupaten Karo, Provinsi Sumatera Utara. Penelitian ini telah dilakukan di blok pemanfaatan kawasan Tahura Tongkoh Kabupaten Karo Provinsi Sumatera Utara dengan metode inventarisasi menggunakan metode garis berpetak yang peletakannya disusun secara sistematik dengan awal purpossive sampling yaitu berdasarkan keberadaan tumbuhan obat yang sudah diketahui oleh masyarakat di sekitar Taman Hutan Raya Tongkoh. Jarak antargaris rintis $200 \mathrm{~m}$ dan jarak antarplot di dalam garis rintis adalah $100 \mathrm{~m}$. Hasil penelitian di Taman Hutan Raya Tongkoh diperoleh 25 jenis tumbuhan obat yang terbagi atas 21 famili. Kerapatan dan frekuensi tumbuhan obat yang tertinggi yaitu spesies pegagan (Centella asiatica) dengan kerapatan sebesar 9.500 individu/hektar dan frekuensi sebesar 0,26 sedangkan jenis pohon yang memiliki frekuensi dan kerapatan tertinggi adalah pinus (Pinus merkusii) dengan frekuensi sebesar 0,2 dan kerapatan 60 individu/hektar.
\end{abstract}

Kata kunci: tumbuhan obat, keragaman

\section{ABSTRACT}

Tongkoh Great Forest Park has an excellent site factor for various types of medicine plants. The research about the medicine plants spesies diversity in Tongkoh Great Forest Park was needed because there was the lack of information about the types of medicine plants in the area. The purpose of the study was to determine the diversity of species and it's abundance, in the area of utilization block area Tongkoh Great Forest Park, Karo District, North Sumatra Province. This research was conducted on August 2014 in the utilization area of Tongkoh Great Forest Park, Karo District, North Sumatra Province by inventory method was employed using the terraced lines method that arranged systematically and started with purposive sampling, based on the presence of medicine plants that had known by local communities in around area. The distance between the pioneer lines were $200 \mathrm{~m}$ and the distance between the plots and the path lines were $100 \mathrm{~m}$. The results of the research show 
that there are 25 species of medicine plants which are divided into 21 families. The most dominant species was pegagan (Centella asiatica) with density about 9,500 individu/hectare and frequency at 0.26 and tree species which have the highest relative density was pine (Pinus merkusii) with frequency was 0.2 and the dnnity was 60 individu/hectare.

Keywords: medicinal plants, diversity

\section{PENDAHULUAN}

Taman Hutan Raya (Tahura) Tongkoh terletak di dua kabupaten yaitu Kabupaten Deli Serdang dan Kabupaten Tanah Karo. Taman Hutan Raya Tongkoh memiliki kondisi tempat tumbuh yang sangat baik untuk berbagai jenis tumbuhan berkhasiat obat. Tumbuhan obat merupakan jenis tumbuhan yang diketahui mempunyai khasiat untuk mengobati penyakit. Dalam kehidupan saat ini masyarakat memiliki kecenderungan untuk kembali ke alam (back to nature) dengan memanfaatkan tumbuhan obat untuk mengobati berbagai penyakit dibandingkan obat-obatan kimia. Namun masyarakat sekitar kawasan Taman Hutan Raya Tongkoh yang berminat untuk memanfaatkan tumbuhan obat sebagai obat alternatif untuk mengobati penyakit menghadapi masalah. Masalah yang dialami oleh masyarakat yaitu kurangnya pengetahuan, data atau informasi yang memadai tentang jenis-jenis tumbuhan yang biasa digunakan sebagai ramuan obat-obatan tradisional (Arief, 2001).

Perumusan masalah dari penelitian ini adalah kurangnya pengetahuan, informasi, jenisjenis, keanekaragaman dan kelimpahan tumbuhan obat yang ada di Taman Hutan Raya Tongkoh. Tujuan dari penelitian ini adalah untuk mengetahui jenis- jenis dan kelimpahan dari masing-masing jenis tumbuhan obat yang ada di blok pemanfaatan kawasan Tahura Tongkoh Kabupaten Karo Provinsi Sumatera Utara.

Manfaat penelitian ini adalah sebagai informasi bagi masyarakat mengenai keberadaan jenis tumbuhan berkhasiat obat yang masih dapat ditemukan di Taman Hutan Raya Tongkoh pada blok pemanfaatan, sebagai masukan bagi instansi kehutanan dan masyarakat pengelola Taman Hutan Raya Tongkoh, sebagai referensi bagi pengembangan ilmu pengetahuan khususnya tentang keanekaragaman jenis tumbuhan berkhasiat obat.

\section{METODE PENELITIAN}

\section{Lokasi dan Waktu Penelitian}

Penelitian ini dilaksanakan di blok pemanfaatan kawasan hutan pendidikan USU Tahura Desa Tongkoh Kabupaten Karo Kecamatan Dolat Rayat Provinsi Sumatera Utara pada bulan Agustus 2014.

\footnotetext{
Alat dan Bahan

Alat yang digunakan dalam penelitian ini meliputi kompas, lembar pengamatan, tali rafia, rol meter,buku kunci determinasi tumbuhan obat, GPS (global positioning system), termometer, kamera digital canon dan pita ukur dengan ketelitian 0,1 mm, sedangkan yang menjadi objek penelitian adalah tumbuhan obat yang berada di Hutan Pendidikan USU Tahura Desa Tongkoh Kecamatan Dolat Rayat, Kabupaten Karo Provinsi Sumatera Utara.
} 


\section{Pelaksanaan Penelitian}

Pelaksanaan penelitian ini terdiri atas 3 tahap, sebagai berikut.

1. Tahap persiapan

Pada tahap persiapan, kegiatan yang dilakukan yaitu menyiapkan alat dan bahan yang akan digunakan pada penelitiaan ini. Kemudian pembuatan 50 petak contoh dengan metode garis berpetak. Petak contoh tersebut berukuran $20 \mathrm{~m} \times 20 \mathrm{~m}$ dengan intensitas sampling 0,2 $\%$. Penempatan petak contoh tersebut disusun secara sistematik dengan awal purpossive sampling.

2. Tahap pelaksanaan

Data yang diambil dalam tahap pelaksanaan penelitian ini meliputi data primer dan data sekunder. Data primer yang diambil meliputi jenis- jenis tumbuhan baik berupa pohon, perdu, liana, dan semak yang berkhasiat obat yang ada di dalam petak contoh. Data Sekunder merupakan data yang sifatnya mendukung data primer yang diperoleh melalui studi literatur, yaitu berupa keadaan umum lokasi penelitian.

3. Analisis Data

Pengolahan data dilakukan dengan mentabulasi data jenis- jenis tumbuhan obat, kemudian dilakukan klasifikasi tumbuhan obat. Analisis data dengan analisis vegetasi digunakan untuk mengetahui komposisi vegetasi. Parameter analisis vegetasi yang diukur adalah sebagai berikut (Indriyanto, 2006).

1. Kerapatan

$$
\mathrm{K}=\frac{\text { jumlah individu suatu jenis ke-i }}{\text { luas seluruh petak contoh }}
$$

2. Frekuensi

$$
F=\frac{\text { jumlah petak contoh ditemukannya suatu jenis ke }-\mathrm{i}}{\text { jumlah seluruh petak contoh }}
$$

\section{HASIL DAN PEMBAHASAN}

\section{A. Hasil Penelitian}

\section{Keragaman Jenis Tumbuhan Obat}

Berdasarkan hasil penelitian yang telah dilakukan di Taman Hutan Raya Tongkoh ditemukan 25 jenis tumbuhan obat yang terbagi atas 21 famili. Semua jenis tumbuhan obat hidup secara liar di dalam Taman Hutan Raya Tongkoh pada Blok Pemanfaatan. Data keragaman jenis tumbuhan obat di Taman Hutan Raya Tongkoh disajikan pada Tabel 1.

Berdasarkan Tabel 1 tumbuhan obat yang ditemukan di Taman Hutan Raya Tongkoh sebagian besar digunakan untuk mengobati penyakit yang tergolong penyakit infeksi. Penyakit infeksi merupakan salah satu golongan penyakit yang disebabkan oleh sejenis virus, bakteri, jamur dan protozoa yang mudah menyerang manusia dan dapat menular secara cepat (Satyareni, 2011). Penyakit ini dapat menular dengan berbagai cara yaitu meliputi kontak fisik, makanan yang terkontaminasi dan melalui udara (Rijaii, 2011). 
Tabel 1. Jenis-jenis tumbuhan obat yang ditemukan di Taman Hutan Raya Tongkoh.

\begin{tabular}{|c|c|c|c|c|}
\hline No & Nama Lokal & Nama Latin & Kegunaan & Jenis Penyakit \\
\hline 1 & Andaliman & Zanthoxylum acanthopodium & Obat epilepsy & $\begin{array}{l}\text { Penyakit } \\
\text { degeneratif }\end{array}$ \\
\hline 2 & Arbei & Rubus reflexus & Obat mata & Penyakit infeksi \\
\hline 3 & Belo-belo & Piper decumanum & Luka, Bengkak & Penyakit infeksi \\
\hline 4 & Besi-besi & Justicia gandarusa & Obat rematik & $\begin{array}{l}\text { Penyakit } \\
\text { degeneratif }\end{array}$ \\
\hline 5 & Bidara & Artemisia vulgaris & Obat ambeyen & $\begin{array}{l}\text { Penyakit } \\
\text { degeneratif }\end{array}$ \\
\hline 6 & Bunga sapa /Tapak dara & Catharanthus roseus & Obat bisul & Penyakit infeksi \\
\hline 7 & Cekala & Nicolaia speciosa & Obat batuk & Penyakit infeksi \\
\hline 8 & Cingkam & Bischofia javanica & Obat maag & Penyakit infeksi \\
\hline 9 & Gagatan harimau & Vitis gracilis & Obat sakit perut & Penyakit infeksi \\
\hline 10 & Kayu manis & Cinnamomum burmanii & Obat diare & Penyakit infeksi \\
\hline 11 & Kelsi & Bidens sinensis & Obat gatal-gatal & Penyakit infeksi \\
\hline 12 & Kembang sepatu & Hibiscus rosasinensis & Obat demam & Penyakit infeksi \\
\hline 13 & Kumis kucing & Orthosiphon stamineus & Obat angin duduk & Penyakit infeksi \\
\hline 14 & Lancing & Solanum verbacifolium & Obat terkilir & Penyakit infeksi \\
\hline 15 & Lenga-lenga & Eupatorium odoratum & Masuk angin & Penyakit infeksi \\
\hline 16 & Pakis/Tenggiang & Polystichum setiferum & Obat Luka & Penyakit infeksi \\
\hline 17 & Pecah pinggan & Centipeda minima & Menyegarkan tubuh & Penurunan stamina \\
\hline 18 & Pegagan & Centella asiatica & Menurunkan gula darah & $\begin{array}{l}\text { Penyakit } \\
\text { degeneratif }\end{array}$ \\
\hline 19 & Pinus & Pinus merkusii & Obat sakit gula & $\begin{array}{l}\text { Penyakit } \\
\text { degeneratif }\end{array}$ \\
\hline 20 & Rotan batu & Calamus diepenhorstii & Obat sakit perut & Penyakit infeksi \\
\hline 21 & Sayat-sayat & Leersia hexandra & Obat sakit gigi & Penyakit infeksi \\
\hline 22 & Senduduk & Melastoma candidum & Obat amandel & Penyakit infeksi \\
\hline 23 & Sibagori & Sida rhombifolia & Obat sakit gigi & Penyakit infeksi \\
\hline 24 & Singkut & Curculigo latifolia & Obat mata & Penyakit infeksi \\
\hline 25 & Surat dibata & Macodes petola & Obat keracunan & Penyakit infeksi \\
\hline
\end{tabular}

Sumber : data primer, 2014

Berdasarkan Tabel 1 jenis tumbuhan obat sebagian besar mengobati penyakit infeksi yaitu sebanyak 16 jenis tumbuhan obat. Penyakit infeksi yang sangat mudah menular, sehingga masyarakat lebih suka menanam jenis tumbuhan obat yang mengobati penyakit infeksi dan tumbuhan obat tersebut cocok untuk tumbuh di Taman Hutan Raya Tongkoh.

\section{Keragaman Famili Tumbuhan Obat}

Hasil penelitian menunjukkan bahwa terdapat 21 famili tumbuhan obat beserta anggotanya yang ada di Taman Hutan Raya Tongkoh secara lengkap disajikan pada Tabel 2 berikut. 
Tabel 2. Famili tumbuhan obat yang ditemukan di Taman Hutan Raya Tongkoh.

\begin{tabular}{|c|c|c|}
\hline No & Famili & Spesies tumbuhan obat \\
\hline 1. & Acanthaceae & 1. Besi- besi (Justicia gandarusa) \\
\hline 2. & Apocynaceae & 1. Bunga sapa / Tapak dara (Catharanthus roseus) \\
\hline 3. & Arecaceae & 1. Rotan batu (Calamus diepenhorstii) \\
\hline \multirow[t]{4}{*}{4.} & Asteraceae & 1. Bidara (Artemisia vulgaris) \\
\hline & & 2. Kelsi (Bidens sinensis) \\
\hline & & 3. Pecah pinggan (Centipeda minima) \\
\hline & & 4. Lenga-lenga (Eupatorium odoratum) \\
\hline 5. & Amaryllidaceae & 1. Singkut (Curculigo latifolia) \\
\hline 6. & Dryopteridaceae & 1. Pakis/ Tenggiang (Polystichum setiferum) \\
\hline 7. & Euphorbiaceae & 1. Cingkam (Bischofia javanica) \\
\hline 8. & Lamiales & 1. Kumis kucing (Orthosiphon stamineus) \\
\hline 9. & Lauraceae & 1. Kayu manis (Cinnamomum burmanii) \\
\hline 10. & Mackinlayaceae & 1. Pegagan (Centella asiatica) \\
\hline \multirow[t]{2}{*}{11.} & Malvaceae & 1. Kembang sepatu (Hibiscus rosasinensis) \\
\hline & & 2. Sibagori (Sida rhombifolia) \\
\hline 12. & Melastomataceae & 1. Senduduk (Melastoma candidum) \\
\hline 13 & Orchidaceae & 1. Surat dibata (Macodes petola) \\
\hline 14. & Pinaceae & 1. Pinus (Pinus merkusii) \\
\hline 15. & Piperaceae & 1. Belo-belo (Piper decumanum) \\
\hline 16. & Poaceae & 1. Sayat-sayat (Leersia hexandra) \\
\hline 17. & Rosaceae & 1. Arbei (Rubus reflexus) \\
\hline 18. & Rutaceae & 1. Andaliman (Zanthoxylum acanthopodium) \\
\hline 19. & Solanaceae & 1. Lancing (Solanum verbacifolium) \\
\hline 20. & Vitaceae & 1. Gagatan harimau (Vitis gracilis) \\
\hline 21. & Zingiberaceae & 1. Cekala (Nicolaia speciosa) \\
\hline
\end{tabular}

Tabel 2 menunjukkan bahwa tumbuhan obat yang paling tinggi ditemukan yaitu tumbuhan yang berasal dari famili Asteraceae. Famili Asteraceae memiliki ciri- ciri yaitu daun tunggal, berbunga majemuk yang berbentuk tabung, tumbuh menyebar dan liar di kawasan yang bersuhu atau berhawa sejuk biasanya lereng gunung (Zuhud, 2009).

\section{Keragaman Habitus Tumbuhan Obat}

Tumbuhan obat yang ditemukan di Taman Hutan Raya Tongkoh terdiri atas beberapa macam habitus. Habitus merupakan bentuk kehidupan tumbuhan atau perawakan tumbuhan yang tampak dari luar (Indriyanto, 2006). Berdasarkan habitusnya tumbuhan obat yang ditemukan di Taman Hutan Raya Tongkoh disajikan pada Tabel 3.

Tabel 3 menunjukkan bahwa jenis tumbuhan obat yang paling banyak dijumpain di Taman Hutan Raya Tongkoh berdasarkan habitusnya yaitu golongan semak. Semak adalah kelompok tumbuhan kormus berkayu yang pada saat dewasa berukuran tubuh lebih kecil daripada perdu dengan tinggi tumbuhan kurang dari $2 \mathrm{~m}$. Perdu adalah kelompok tumbuhan kormus berkayu yang pada saat dewasa berukuran tubuh lebih kecil daripada pohon dengan tinggi tumbuhan 2--5 m (Indriyanto, 2012). 
Tabel 3. Pengelompokan jenis-jenis tumbuhan obat yang ditemukan di Taman Hutan Raya Tongkoh berdasarkan habitus.

\begin{tabular}{|c|c|c|}
\hline Habitus & Spesies tumbuhan & Kegunaan \\
\hline \multirow{4}{*}{ Liana } & 1. Rotan batu (Calamus diepenhorstii) & Obat sakit perut \\
\hline & 2. Belo-belo (Piper decumanum ). & Luka, bengkak \\
\hline & 3. Pecah pinggan (Centipeda minima) & Menyegarkan tubuh \\
\hline & 4. Pegagan (Centella asiatica) & Menurunkan gula darah \\
\hline \multirow[t]{13}{*}{ Semak } & 1. Andaliman (Zanthoxylum & Obat epilepsy \\
\hline & acanthopodium) & Obat mata \\
\hline & 2. Arbei(Rubus reflexus) & Obat batuk \\
\hline & 3. Cekala(Nicolaia speciosa) & Obat gatal- gatal \\
\hline & 4. Kelsi (Bidens sinensis) & Obat sakit gigi \\
\hline & 5. Sibagori (Sida rhombifolia) & Obat mata \\
\hline & 6. Singkut (Curculigo latifolia) & Masuk angin, pegal- \\
\hline & 7. Lenga-lenga (Eupatorium odoratum) & pegal \\
\hline & 8. Bidara (Artemisia vulgaris) & Obat ambeyen \\
\hline & 9. Sayat-sayat (Leersia hexandra) & Obat sakit gigi \\
\hline & 10. Bunga sapa (tapak dara)(Catharanthus & Obat bisul \\
\hline & roseus) & Obat keracunan \\
\hline & 11. Surat dibata (Macodes petola). & \\
\hline \multirow[t]{7}{*}{ Perdu } & 1. Besi-besi (Justicia gandarusa) & Obat rematik \\
\hline & 2. Gagatan harimau(Vitis gracilis) & Obat sakit perut \\
\hline & 3. Kembang sepatu (Hibiscus rosasinensis) & Obat demam \\
\hline & 4. Kumis kucing (Orthosiphon stamineus) & Obat angin duduk \\
\hline & 5. Lancing (Solanum verbacifolium) & Obat terkilir \\
\hline & 6. Senduduk (Melastoma candidum) & Obat amandel \\
\hline & 7. Tenggiang (Polystichum setiferum). & Obat luka \\
\hline \multirow[t]{3}{*}{ Pohon } & 1. Cingkam(Bischofia javanica) & Obat maag \\
\hline & 2. Pinus (Pinus merkusii) & Obat sakit gula \\
\hline & 3. Kayu manis (Cinnamomum burmanii). & Obat diare \\
\hline
\end{tabular}

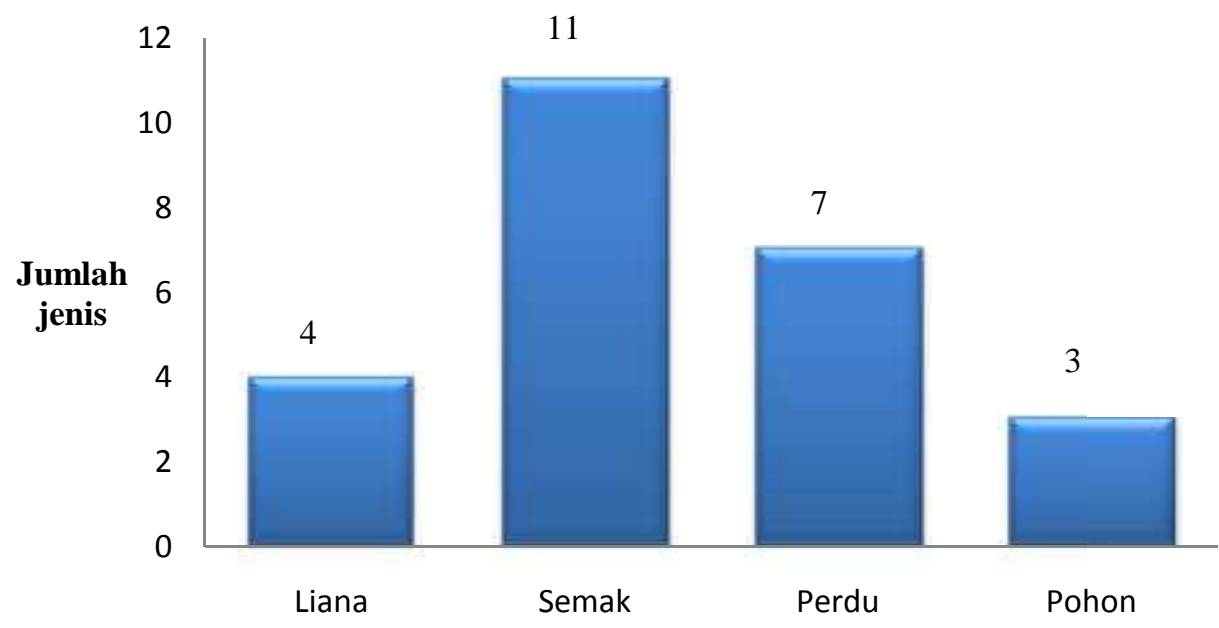

Habitus

Gambar 5. Histogram jumlah jenis tumbuhan obat tiap habitus yang terdapat di Taman Hutan Raya Tongkoh. 


\section{Kerapatan dan Frekuensi Jenis Tumbuhan Obat}

Kerapatan dan frekuensi jenis tumbuhan obat yang ditemukan di lokasi penelitian Taman Hutan Raya Tongkoh disajikan pada Tabel 4.

Tabel 4. Kerapatan dan frekuensi setiap jenis tumbuhan obat yang terdapat di Blok pemanfaatan dalam Taman Hutan Raya Tongkoh.

\begin{tabular}{|c|c|c|c|c|}
\hline No & Nama Lokal & Nama Imiah & $\begin{array}{c}\text { Kerapatan } \\
\text { (individu/hektar) }\end{array}$ & Frekuensi \\
\hline 1. & Andaliman & $\begin{array}{l}\text { Zanthoxylum } \\
\text { acanthopodium }\end{array}$ & 750 & 0,06 \\
\hline 2. & Arbei & Rubus reflexus & 500 & 0,02 \\
\hline 3. & Belo-belo & Piper decumanum & 5.500 & 0,12 \\
\hline 4. & Besi-besi & Justicia gandarusa & 664 & 0,08 \\
\hline 5. & Bidara & Artemisia vulgaris & 7.250 & 0,24 \\
\hline 6. & $\begin{array}{l}\text { Tapak dara /Bunga } \\
\text { sapa }\end{array}$ & Catharanthus roseus & 6.000 & 0,10 \\
\hline 7. & Cekala & Nicolaia speciosa & 2.000 & 0,22 \\
\hline 8. & Cingkam & Bischofia javanica & 7 & 0,10 \\
\hline 9. & Gagatan harimau & Vitis gracilis & 688 & 0,12 \\
\hline 10. & Kayu manis & Cinnamomum burmanii & 7,5 & 0,08 \\
\hline 11. & Kelsi & Bidens sinensis & 4.150 & 0,12 \\
\hline 12. & Kembang sepatu & Hibiscus rosasinensis & 200 & 0,04 \\
\hline 13. & Kumis kucing & Orthosiphon stamineus & 3.750 & 0,08 \\
\hline 14. & Lancing & Solanum verbacifolium & 6.400 & 0,30 \\
\hline 15. & Lenga-lenga & Eupatorium odoratum & 1.136 & 0,22 \\
\hline 16. & Pakis/ Tenggiang & Polystichum setiferum & 200 & 0,16 \\
\hline 17. & Pecah Pinggan & Centipeda minima & 2.700 & 0,08 \\
\hline 18. & Pegagan & Centella asiatica & 9.500 & 0,26 \\
\hline 19. & Pinus & Pinus merkusii & 60 & 0,20 \\
\hline 20. & Rotan batu & Calamus diepenhorstii & 16 & 0,04 \\
\hline 21. & Sayat-sayat & Leersia hexandra & 5.650 & 0,14 \\
\hline 22. & Senduduk & Melastoma candidum & 912 & 0,12 \\
\hline 23. & Sibagori & Sida rhombifolia & 4.750 & 0,10 \\
\hline 24. & Singkut & Curculigo latifolia & 1.000 & 0,16 \\
\hline 25. & Surat dibata & Macodes petola & 1.500 & 0,16 \\
\hline \multicolumn{3}{|c|}{ Jumlah total } & $65.290,5$ & 3,32 \\
\hline
\end{tabular}

Tabel 4 menunjukkan bahwa kerapatan dan frekuensi setiap jenis tumbuhan obat berbeda- beda. Kerapatan menunjukkan jumlah jenis tumbuhan obat per satuan luas. Frekuensi merupakan jumlah plot yang di dalamnya terdapat tumbuhan obat per jumlah keseluruhan plot. Jenis tumbuhan obat yang memiliki kerapatan tertinggi dan frekuensi tertinggi yaitu pegagan (Centella asiatica) dengan kerapatan, yaitu sebesar 9.500 individu/ hektar dan frekuensi sebesar 0,26, sedangkan untuk jenis tumbuhan obat yang memiliki kerapatan terendah yaitu cingkam (Bischofia javanica) yaitu sebesar 7 individu/ hektar dan frekuensi terendah yaitu arbei (Rubus reflexus) yaitu sebesar 0,02 . 


\section{Pembahasan}

Berdasarkan hasil pengamatan di 50 plot pada wilayah blok pemanfaatan dalam kawasan Taman Hutan Raya Tongkoh ditemukan 25 jenis tumbuhan obat yang terbagi 21 famili. Semua jenis tumbuhan ini hidup secara liar. Berdasarkan jumlah jenis, tumbuhan obat mengalami penurunan jika dibandingkan dengan hasil penelitian yang telah dilakukan oleh Riwanda pada tahun 2012. Riwanda (2012), melaporkan bahwa pada tahun 2012 ditemukan 38 jenis tumbuhan obat yang terbagi atas 23 ordo dan 24 famili.

Beberapa jenis tumbuhan obat yang ditemukan merupakan jenis yang dibudidayakan di luar kawasan oleh masyarakat sekitar Taman Hutan Raya Tongkoh. Penurunan beberapa jenis tumbuhan obat disebabkan karena beberapa jenis tumbuhan obat bukan tanaman asli kawasan Taman Hutan Raya Tongkoh. Hal ini disebabkan oleh adanya perubahan status kawasan dari hutan lindung ke hutan konservasi, di mana hutan lindung masyarakat diperbolehkan untuk mengelola lahan pada kawasan tersebut sedangkan pada hutan konservasi masyarakat tidak diperbolehkan mengelola lahan, sehingga bentuk pengolahan lahan akan berbeda. Oleh karena itu beberapa jenis tumbuhan obat tidak dapat tumbuh dengan baik karena kondisi tempat tumbuh yang tidak sesuai dan adanya persaingan yang tinggi antara tumbuhan obat dan tumbuhan yang lain di Taman Hutan Raya Tongkoh.

Berdasarkan Tabel 3 dapat diketahui bahwa tumbuhan obat yang berhabitus semak memiliki jumlah jenis tertinggi. Hal ini dikarenakan semak dan perdu biasanya tumbuh cepat jika dibandingkan dengan pohon atau tumbuhan lainnya yang bukan tumbuhan obat. Menurut Abdiyani (2008), semak dan perdu hidup dengan liar, mudah ditanam atau tumbuh lebih cepat di berbagai kondisi wilayah baik dataran tinggi maupun dataran rendah sehingga jumlah jenis semak dan perdu berlimpah jika dibandingkan dengan pohon.

Tabel 4 menunjukkan kerapatan dan frekuensi tumbuhan obat di Taman Hutan Raya Tongkoh. Tajuk pohon yang bukan tumbuhan obat, memiliki penutupan tajuk sangat rapat jika dibandingkan dengan tajuk tumbuhan obat yang bukan pohon dan untuk tumbuhan obat yang berupa pohon juga tidak terlalu rapat, sehingga beberapa jenis tumbuhan obat yang bukan pohon dan pohon kalah bersaing dengan pohon yang bukan tumbuhan obat. Menurut Karmilasanti (2011), penutupan tajuk pohon yang rapat menyebabkan tumbuhan yang bukan pohon kalah bersaing dengan pohon.

Kerapatan tertinggi di antara tumbuhan obat yang ditemukan adalah pegagan (Centella asiatica) sebesar 9.500 individu/ hektar. Tumbuhan obat yang jarang ditemukan adalah arbei (Rubus reflexus) dan cingkam (Bischofia javanica). Pegagan memiliki kerapatan yang tinggi dibandingkan dengan tumbuhan obat lainnya. Hal tersebut dikarenakan tempat tumbuh pegagan cocok di daerah tersebut. Menurut Darwati (2012), pegagan dapat tumbuh di tempat yang lembab dan ternaugi, ditempat lembab dengan naugan yang cukup helaian daun pegagan berukuran lebih besar dan tebal sehingga penyebaran pegagan sangat mudah dengan bantuan angin atau hewan.

Tumbuhan obat cingkam (Bischofia javanica) memiliki kerapatan yang lebih rendah. Tumbuhan obat jenis pohon ini biasanya tumbuh di daerah yang memiliki ketinggian kurang dari $1.500 \mathrm{~m}$ dpl. Cingkam (Bischofia javanica) masih sulit dibudidayakan karena merupakan pohon yang tumbuh secara liar di hutan atau hutan jati (Utomo, 2013) dan untuk frekuensi terendah yaitu arbei (Rubus reflexus). Tumbuhan obat arbei biasanya tumbuh dengan subur di daerah terbuka. Kondisi daerah yang lembab menyebabkan tumbuhan arbei tidak cocok untuk tumbuh di daerah ini sehingga kisaran hidupnya sempit dan rendah.

Penyebaran tumbuhan ini juga sangat sulit sehingga kerapatan tumbuhan obat ini rendah (Darwati, 2012). Tumbuhan obat yang sudah mengalami penurunanan populasi dan tidak lagi ditemukan di Taman Hutan Raya Tongkoh perlu dilakukan pembudidayaan, sebagai contoh kemenyan (Styrax sumaterana), kulit labang (Castanopsis costata), surindan (Scrrulla ferruginea) dan jenis- jenis tumbuhan obat yang lainnya (Riwanda, 2012). 
Budidaya tumbuhan obat yang ada di dalam kawasan Taman Hutan Raya Tongkoh perlu dilakukan untuk menghindari pengambilan dari hutan secara langsung yang dapat menyebabkan kelangkaan jenis- jenis yang diambil secara berlebihan. Pengembangan tumbuhan tidak jauh dari habitat aslinya dapat mempertahannkan keunggulan genetik tumbuhan obat tersebut (Abdiyani, 2008).

\section{KESIMPULAN DAN SARAN}

\section{Kesimpulan}

Berdasarkan hasil penelitian yang telah dilakukan, dapat disimpulkan bahwa.

1. Terdapat 25 jenis tumbuhan yang berkhasiat obat yang terbagi atas 21 famili di Taman Hutan Raya Tongkoh. Terjadi penurunan jumlah tumbuhan obat dari tahun 2012-2014 yaitu sebanyak 13 spesies.

2. Spesies tumbuhan obat yang memiliki kelimpahan tertinggi yaitu pegagan (Centella asiatica) dengan kerapatan dan frekuensi yang paling tinggi, yaitu sebesar 9.500 individu/ hektar dan frekuensi sebesar 0,26 dan pohon tergolong rendah dilihat dari persentasinya.

\section{DAFTAR PUSTAKA}

Abdiyani, S. 2008. Keanekaragaman jenis tumbuhan bawah berkhasiat obat di dataran tinggi dieng. Jurnal Penelitian Hutan dan Konservasi Alam. Balai Penelitian Kehutanan Solo. Vol. V No. 1 : 79—92 p.

Arief, A. 2001. Hutan dan Kehutanan. Buku. Kanisius. Yogyakarta. Kawasan Taman Hutan Raya Bukit Barisan Desa Tongkoh Kabupaten Karo. Departemen Kehutanan USU.(Belum dipublikasikan). Medan.180 p.

Darwati, I. 2012. Budidaya dan pasca panen pegagan (Centella asiatica). Artikel majalah. Badan Penelitian dan Pengembangan Perkebunan Balai Penelitian Tanaman Rempah dan Obat (BALITTRO). Jakarta. 25 p.

Indriyanto. 2006. Ekologi Hutan. Buku. Bumi aksara. Jakarta. 210 p.

Indriyanto. 2012. Dendrologi: Suatu Teori dan Praktik Menyidik Pohon. Buku. Lembaga Penelitian Universitas Lampung. Bandar Lampung. 232 p.

Karmilasanti, S. 2011. Keanekaragaman jenis tumbuhan obat dan pemanfaatannya di kawasan tane' oleh desa setulang malinau, kalimantan timur. Jurnal Penelitian Dipterokarpa. Vol 5. No.1. Kalimantan Timur.

Rijaii, L. 2011. Penentuan kriteria ilmiah potensi tumbuhan obat unggulan Kelompok Bidang Ilmu Kimia Farmasi. Jurnal Kesehatan. Vol 1. No. 2. Fakultas Farmasi, Universitas Mulawarman. Samarinda.

Riwanda, S. 2012. Keanekaragaman vegetasi tanaman obat di Tahura Bukit Barisan Selatan Tongkoh Kabupaten Karo. Skripsi. Mahasiswa Kehutanan Universitas Sumatera Utara. $65 \mathrm{p}$.

Satyareni, D. 2011. Sistem pakar diagnosis penyakit infeksi tropis dengan menggunakan forward dan backward chaining. Jurnal Teknologi. Vol. 1 No. 2. Fakultas Teknik, Universitas Pesantren Tinggi Darul 'Ulum'. Jombang.

Utomo, B. 2013. Tanaman Obat di Hutan Pendidikan Sumatera Utara Kawasan Tahura Tongkoh. Buku. Universitas Sumatera Utara. Medan. 43 p. 
Zuhud, E, A, M. 2009. Kebijakan Pembangunan Kesehatan Masyarakat Indonesia yang Bhinneka Tunggal Ika dengan Pengembangan Potensi Lokal Ethno-Forest-Pharmacy (Ethno-Wanafarma) pada Setiap Wilayah Sosial-Biologi Satu-satuan Masyarakat Kecil. Departemen Konservasi Sumberdaya Hutan dan Ekowisata. Fakultas Kehutanan IPB. Seminar di Yogyakarta. 